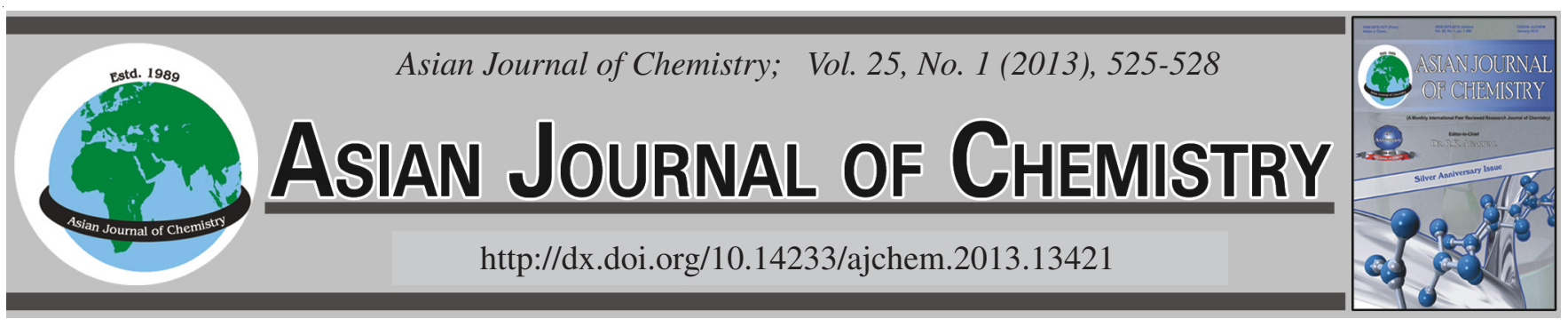

\title{
Synthesis of Alumina-Containing Hexagonal Mesoporous \\ Silica and Its Application in the Adsorption of Gossypol
}

\author{
Shihong Dong, Mingyuan Zhu ${ }^{*}$ and Bin Dai ${ }^{*}$
}

School of Chemistry and Chemical Engineering/Key Laboratory for Green Processing of Chemical Engineering of Xinjiang Bingtuan, Shihezi University, Shihezi Xinjiang 832003, P.R. China

*Corresponding authors: Fax: +86 99 32057270; Tel: +86 99 32057277; E-mail: zhuminyuan@ @hzu.edu.cn; db_tea@ shzu.edu.cn

\begin{abstract}
Mesoporous molecular catalyst alumina-containing hexagonal mesoporous silica (Al-HMS) of different Si/Al ratios have been synthesize by neutral templating method and characterized by X-ray powder diffraction and Brunauer-Emmett-Teller (BET). These dates confirmed the hexagonal mesoporous structure formation at different $\mathrm{Si} / \mathrm{Al}$ ratios. The Al-HMS as catalyst applying to adsorb gossypol in cottonseed oil and gossypol adsorption increased with the amount of Al loading. Under the optimal conditions, the gossypol adsorption was more than $60 \%$.
\end{abstract}

Key Words: Gossypol, Alumina, Hexagonal mesoporous silica, Adsorption.

\section{INTRODUCTION}

Gossypol was disvovered by J.J. Longmore and first purified by L. Marchlewski at end of the 19th century ${ }^{1}$. The gossypol $\left(1,1^{\prime}, 6,6\right.$ '7,7'-hexahydroxy-5,5'-diisopropyl-3-3'-dimethyl-2,2'binaphthanlene-8,8'-dicarboxalydehyde) contained in pigment glands and is a polyphenolic binaphthyl dialdehyde ${ }^{2,3}$, which are distributed the cottonseed. Gossypol is a toxic substance of phenolic compound to young ruminants and monogastric animals ${ }^{4}$. It limits most of the cottonseed products to human and animals. Cottonseed oil is extracted from seeds of the cotton plant and belonged to vegetable oil. Due to the presence of toxic gossypol in cottonseed oil and this oil has a colour fixed which is characterized by a reddish brown colour and is difficult to refine $e^{5,6}$, it can not be used for edible and can infertility in humans. It is necessary for extracted oil and as meal used to be further processed to removal gossypol.

In order to efficiently removal gossypol from cottonseed oil, a number of studies have been carried out, usually through caustic reining ${ }^{7}$ and adsorption on solids, such as activated alumina $^{8}$ and activated montmorillonite-containing clays ${ }^{9}$. Richard et $a l .{ }^{10}$ investigated that aluminas and silicas as adsorbents for reducing the gossypol from cottonseed oil, they found gossypol has a high affinity for alumina surface. Zhao et al. ${ }^{11}$ recent studies reported that alumina-containing hexagonal mesoporous silica (Al-HMS) mesoporous molecular sieve showed good adsorption as a solid catalyst applied to non-methane volatile organic compounds (VOCs).
In this paper, we describe the synthesized of immobilized $\mathrm{Al}$ on hexagonal mesoporous silica (HMS) sieve by a hydrothermal synthesized method. The aluminium-hexagonal mesoporous silica was applied as a solid catalyst for the adsorption of gossypol and characterized by X-ray diffraction (XRD) and Brunauer-Emmett-Teller (BET). The loading of $\mathrm{Al}$ on hexagonal mesoporous silica, the amount of catalyst, the reaction time and reaction temperature were investigated to optimize the reaction conditions for adsorption of gossypol.

\section{EXPERIMENTAL}

The powder X-ray diffraction (XRD) data was collected on a Brunker D8 Advance $\mathrm{X}$-ray diffractometer using $\mathrm{Cu}-\mathrm{K}_{\alpha}$ irradiation $(\lambda=1.5406 \AA)$ as source at $40 \mathrm{kV}$ and $40 \mathrm{~mA}$. The samples were recorded from 1 to $20^{\circ}(2 \theta)$ with a step scan of $0.01 \%$ s.

Brunauer-Emmett-Teller (BET) surface area analysis was performed from the nitrogen adsorption isotherms at $77 \mathrm{~K}$ using a Micromeritics Model ASAP 2020 instrument. All samples were degassed at $110^{\circ} \mathrm{C}$ under vacuum for $6 \mathrm{~h}$. Average pore diameter (d) and pore volume were calculated based on the Barret-Joyner-Halenda (BJH) method.

The $\mathrm{NH}_{3}$-temperature programmed desorption ( $\mathrm{NH}_{3}$-TPD) data were collected using a ChemBet 3000 analyzer. About $120 \mathrm{mg}$ samples were activated under flowing heat $\left(650^{\circ} \mathrm{C}\right)$ for $1.5 \mathrm{~h}$ and cooled to $80{ }^{\circ} \mathrm{C}$ under continuous evacuation. The sample was equilibrated with gaseous $\mathrm{NH}_{3}$ at $0.04 \mathrm{kPa}$ and the temperature increased by $10{ }^{\circ} \mathrm{C} / \mathrm{min}$ under flowing heat $20 \mathrm{~cm}^{3} / \mathrm{min}$. 
The laboratory centrifugation was supplied by An Ting scientific instrument factory, Shanghai and model is TDL802B. The gossypol was detected on high performance liquid chromatography (Waters model 2487, USA).

Pure drug sample of gossypol was kindly supplied by $\mathrm{Ci}$ Yuan Bio Co., Ltd. (Xi'an, China); the cottonseed oil was kindly supplied by Shihezi edible oil refinery. All chemicals were of analytical reagent grades, methanol is chromatographically pure and distilled water was used throughout.

Catalyst preparation: The aluminium-hexagonal mesoporous silica aluminium-hexagonal mesoporous silica catalyst was synthesized according to a procedure described by Zhao et al. ${ }^{11}$. To a vigorously stirred mixture solution of dodecylamine (DDA) in ethanol (EtOH) and deionized water was added at a time a homogenous mixture of 0.2 mol tetraethyl orthosilicate (TEOS) in EtOH and alumina isopropoxide $\left[\mathrm{Al}(\mathrm{O}-\mathrm{i}-\mathrm{Pr})_{3}\right]$ at room temperature.

The mixture was vigorously stirred at room temperature for $24 \mathrm{~h}$, the as-synthesized hexagonal mesoporous silica and aluminium-hexagonal mesoporous silica were filtered, washed with deionized water and dried at room temperature for $24 \mathrm{~h}$. The obtained samples were calcined in a muffle furnace at $c a$. $550{ }^{\circ} \mathrm{C}$ for $5 \mathrm{~h}$.

Adsorption of gossypol: For the purpose of this study, gossypol soluble in refined cottonseed oil and prepared to 0.17 $\mathrm{mg} / \mathrm{g}$ gossypol solution. The gossypol solution stored at $2{ }^{\circ} \mathrm{C}$ in a brown bottle. At the beginning of the reaction, the aluminium-hexagonal mesoporous silica catalyst was handed by ultrasonic dispersion. The adsorption experiments were conducted at room temperature as follows: gossypol solution was charged in a stoppered Erlenmeyer flask and a known amount of the catalyst aluminium-hexagonal mesoporous silica was added to the flask which then shaken vigorously for a significant time. Allowing the catalyst reach to adsorption equilibrium, followed by laboratory centrifugation for $10 \mathrm{~min}$ at $5000 \mathrm{xg}$. The precipitation was filtered through Whatman No. 1 filter paper. The resultant bottom layer was composed of catalyst and gossypol and the supernatant layer was cottonseed oil and retained gossypol which was taken using high performance liquid chromatography to detect.

Detection method: The detection method of gossypol in cottonseed oil according to a procedure described previously ${ }^{12}$. The chromatographic conditions: a $\mathrm{C} 18$ reversed-phase column was used. The particle size was $5 \mu \mathrm{m}$ and the column dimensions were $4.6 \mathrm{~mm} \times 150 \mathrm{~mm}$, the mobile phase were methanol and $2 \%$ phosphoric acid solution (90:10), the column temperature was $40^{\circ} \mathrm{C}$, the flow rate was $1 \mathrm{~mL} / \mathrm{min}$ and the gossypol was detected by a Waters 2487 UV detector at $235 \mathrm{~nm}$, the sensitivity is 0.01-0.02 absorbance unit full scale (AUFS) and the injection volume is $20 \mu \mathrm{m}$. The supernatant layer was mixed with $1 \mathrm{~mL}$ of hexane and $5 \mathrm{~mL}$ of solvent mixture which was $\mathrm{N}, \mathrm{N}$-dimethyl formamide:water $(70: 30, \mathrm{v} / \mathrm{v})$. The samples were stirring for $10 \mathrm{~min}$ and standing for $15 \mathrm{~min}$. The bottom layer was filter and injected into the HPLC.

\section{RESULTS AND DISCUSSION}

Fig. 1 displays the typical XRD pattern for the aluminiumhexagonal mesoporous silica samples with different ZS loading.
It can be clearly seen that the patterns all contain an intense diffraction peak about $2 \theta=2.5^{\circ}$ and exhibited a single (100) peak. The XRD patterns had the typical characteristic peaks of a mesoporous molecular sieve in agreement with the literature reports ${ }^{13,14}$. It can be note that the XRD diffraction peaks of aluminium-hexagonal mesoporous silica $(\mathrm{Si} / \mathrm{Al}=25)$ are much weaker than that of other samples and with the increase of $\mathrm{Al}$ content the $\mathrm{d}$ spacing decrease. Cause of this phenomenon is due to the catalyst reduction in hexagonal order ${ }^{15}$.

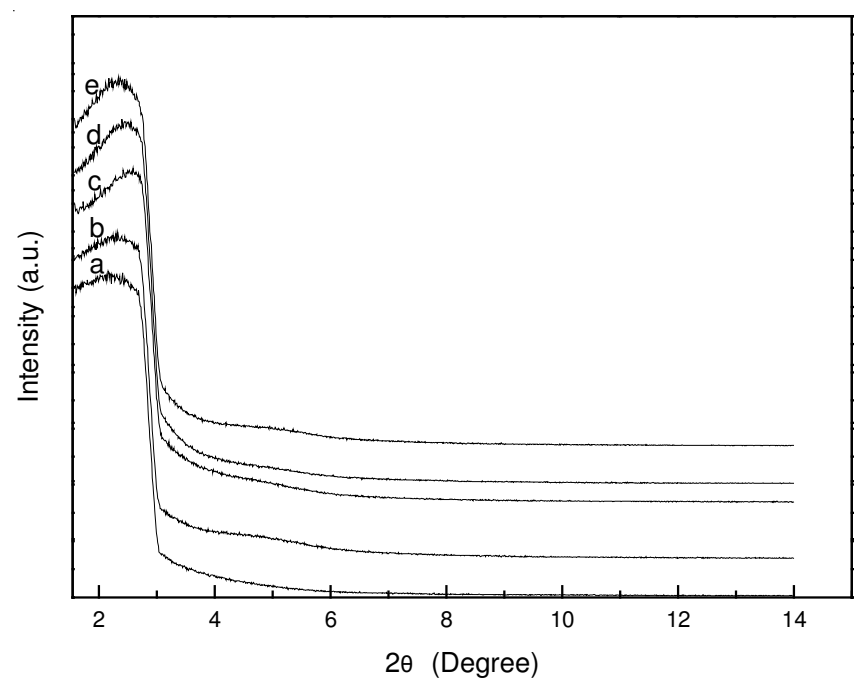

Fig. 1. XRD patterns of aluminium-hexagonal mesoporous silica material for different $\mathrm{Si} / \mathrm{Al}$ ratios: (a) $\mathrm{Si} / \mathrm{Al}$ ratios $=25$, (b) $\mathrm{Si} / \mathrm{Al}$ ratios $=20$, (c) $\mathrm{Si} / \mathrm{Al}$ ratios $=75$, (d) $\mathrm{Si} / \mathrm{Al}$ ratios $=100$ and (e) $\mathrm{Si} / \mathrm{Al}$ ratios $=150$

Table-1 shows surface area and pore size distribution data of the aluminium-hexagonal mesoporous silica samples. It is noted that the surface area and pore volume decreases with increase of $\mathrm{Al}$ into the hexagonal mesoporous silica structure. Some $\mathrm{Al}^{3+}$ ions escape from the catalyst framework and some inter-particle pores are damaged reduced to the pore volume decreased ${ }^{11}$. As higher Al loads, the dealumination of framework during calcinations or the increase of the wall thickness of aluminium-hexagonal mesoporous silica catalyst ${ }^{16}$. The pore volume reduced from $1.44 \mathrm{~cm}^{3} / \mathrm{g}$ to $0.95 \mathrm{~cm}^{3} / \mathrm{g}$. Fig. 2 shows pore size distributions of the obtained various aluminiumhexagonal mesoporous silica samples. It can be seen that the pore sizes of the aluminium-hexagonal mesoporous silica catalyst decrease with increment of Al loading. These results were in agreement with the XRD date which hexagonal order is decreasing with the decrease of $\mathrm{Si} / \mathrm{Al}$ ratio.

\begin{tabular}{cccc}
\multicolumn{4}{c}{ TABLE-1 } \\
\multicolumn{4}{c}{ STRUCTURE OF VARIOUS Al-HMS SAMPLES } \\
\hline Sample & $\mathrm{S}_{\mathrm{BET}}\left(\mathrm{m}^{2} / \mathrm{g}\right)$ & $\mathrm{d}(\mathrm{nm})$ & Pore volume $\left(\mathrm{cm}^{3} / \mathrm{g}\right)$ \\
\hline $\mathrm{Si} / \mathrm{Al}=25$ & 1315 & 4.1 & 1.44 \\
$\mathrm{Si} / \mathrm{Al}=50$ & 1279 & 4.2 & 1.42 \\
$\mathrm{Si} / \mathrm{Al}=75$ & 1219 & 4.2 & 1.28 \\
$\mathrm{Si} / \mathrm{Al}=100$ & 1138 & 4.4 & 1.17 \\
$\mathrm{Si} / \mathrm{Al}=150$ & 1100 & 4.4 & 1.18 \\
\hline
\end{tabular}

Fig. 3 shows the $\mathrm{N}_{2}$ adsorption-desorption isotherms of the aluminium-hexagonal mesoporous silica samples with different Al loading. The samples of aluminium-hexagonal 


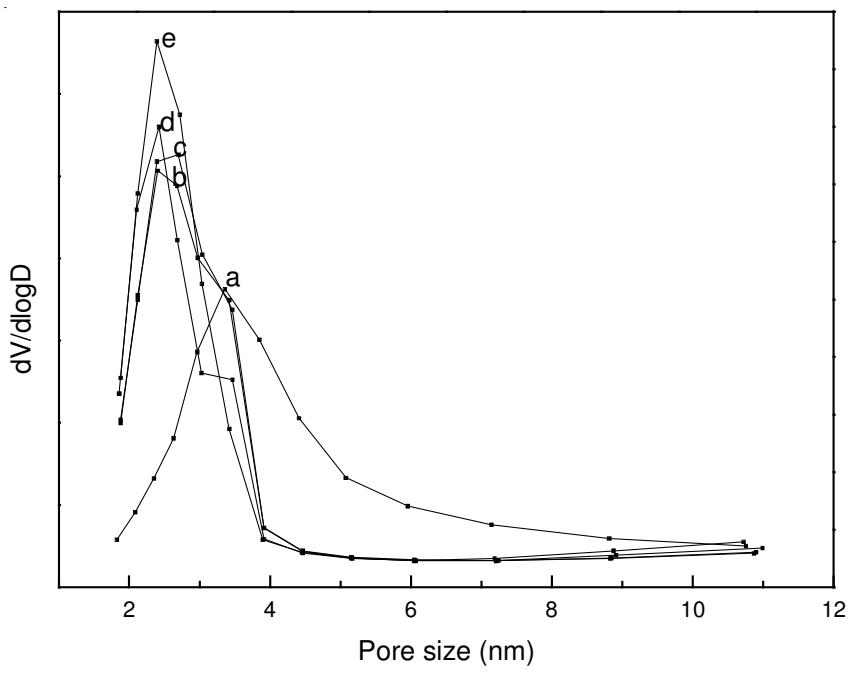

Fig. 2. Pore size distributions for different $\mathrm{Si} / \mathrm{Al}$ ratios: (a) $\mathrm{Si} / \mathrm{Al}=25$, (b) $\mathrm{Si} / \mathrm{Al}=20$, (c) $\mathrm{Si} / \mathrm{Al}=75$, (d) $\mathrm{Si} / \mathrm{Al}=100$ and (e) $\mathrm{Si} / \mathrm{Al}=150$

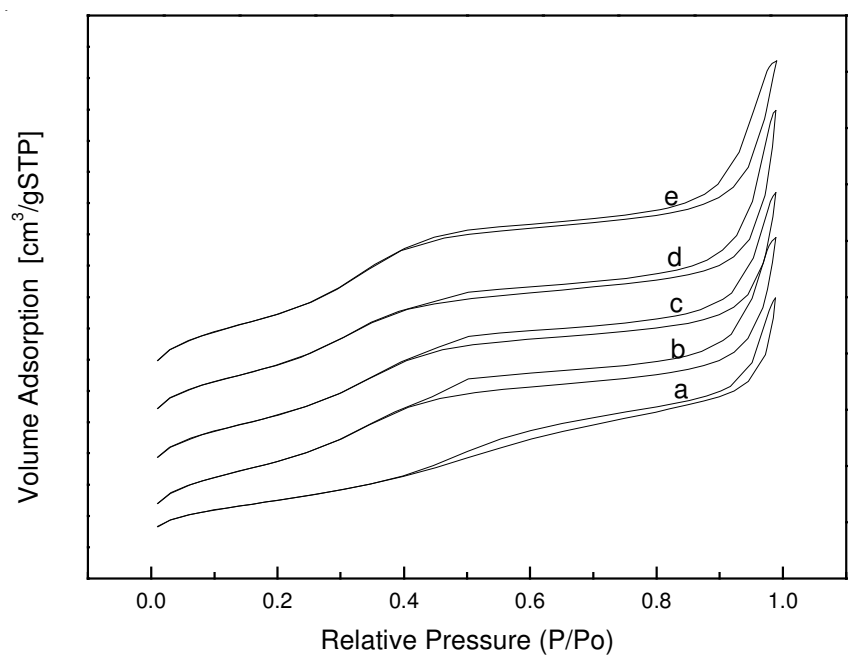

Fig. 3. Nitrogen adsorption isotherms for different $\mathrm{Si} / \mathrm{Al}$ ratios: (a) $\mathrm{Si} / \mathrm{Al}=$ 25 , (b) $\mathrm{Si} / \mathrm{Al}=50$, (c) $\mathrm{Si} / \mathrm{Al}=75$, (d) $\mathrm{Si} / \mathrm{Al}=100$ and (e) $\mathrm{Si} / \mathrm{Al}=$ 150

mesoporous silica catalysts exhibited the shape of II isotherms according to the IUPAC classification for nitrogen adsorptiondesorption isotherms. All samples exhibit a well-defined hysteresis loop in the adsorption curve at about $\mathrm{P} / \mathrm{P}_{\mathrm{o}}=0.42$, which is indicative of the filling of framework-confined mesopores.

There are a number of methods for acidity measurements ${ }^{17,18}$. The solid acid sites are determined by TPD which adsorption of ammonia to determine total acidity and acid strength distribution. It is evident from the $\mathrm{NH}_{3}$-TPD profiles that aluminiumhexagonal mesoporous silica materials of $\mathrm{Si} / \mathrm{Al}$ ratios ranging from 25 to 150 are shown in Fig. 4. It can be inferred that the acidity was increased on increasing the Al loading on hexagonal mesoporous silica content. Falaras et al. ${ }^{9}$ reported that adsorption phenomenon in cottonseed oil is mainly involves the pigment such as gossypol, carotene and so on; the pigment attraction to the acid sites in the adsorbent.

The effects of mass loading the $\mathrm{Al}$ on hexagonal mesoporous silica (molar ratio) for gossypol adsorption present in Fig. 5. At ambient temperature, $2 \mathrm{~g}$ cottonseed oil and the gossypol content of $0.17 \mathrm{mg} / \mathrm{g}$, the amount of aluminium-hexagonal

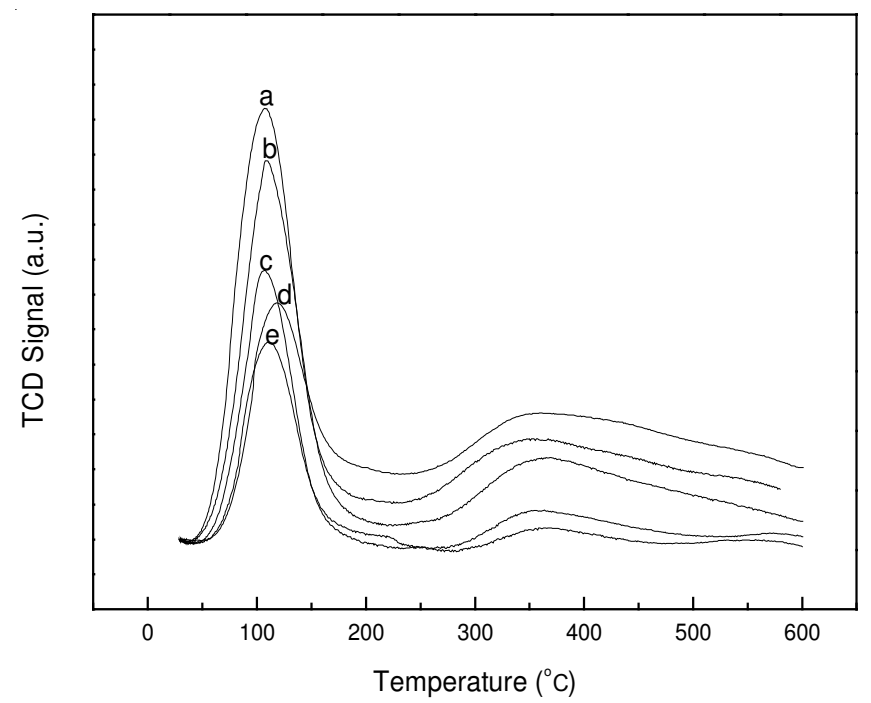

Fig. 4. $\mathrm{NH}_{3}$-TPD curves for (a) $\mathrm{Si} / \mathrm{Al}=25$, (b) $\mathrm{Si} / \mathrm{Al}=50$, (c) $\mathrm{Si} / \mathrm{Al}=75$, (d) $\mathrm{Si} / \mathrm{Al}=100$ and (e) $\mathrm{Si} / \mathrm{Al}=150$

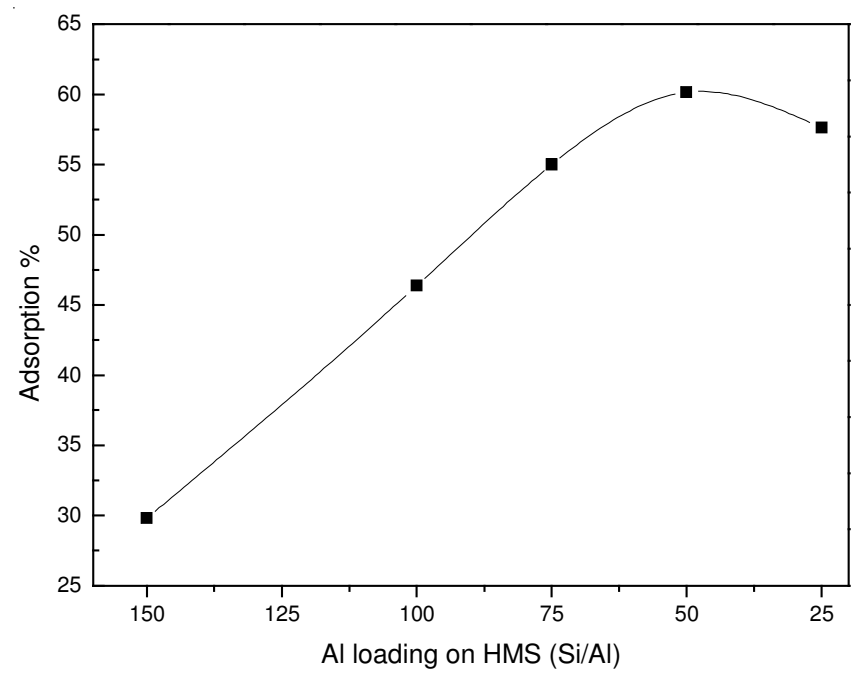

Fig. 5. Catalytic activities of solid acid catalysts with different Al loading on hexagonal mesoporous silica for adsorption of gossypol

mesoporous silica catalyst was $0.05 \mathrm{~g}$. The mixture was stirred at $200 \mathrm{rpm}$ for $0.5 \mathrm{~h}$. It is shown that the adsorption rate of gossypol increased with increasing Al loading on the hexagonal mesoporous silica molecular sieve and when $\mathrm{Si} / \mathrm{Al}$ was 150 , the aluminium-hexagonal mesoporous silica catalyst adsorbed gossypol is $29.82 \%$; $\mathrm{Si} / \mathrm{Al}$ was 100 , the adsorbed gossypol is $46.37 \%$; $\mathrm{Si} / \mathrm{Al}$ was 75 , the adsorbed gossypol is $55 \%$; $\mathrm{Si} / \mathrm{Al}$ was $60.15 \%$, the adsorbed gossypol is $60.15 \%$ and $\mathrm{Si} / \mathrm{Al}$ was 25 , the adsorbed gossypol is $57.64 \%$. When $\mathrm{Si} / \mathrm{Al}$ was 50 , no further increase was observed at more Al loading on hexagonal mesoporous silica.

At the same time, the amount of aluminium-hexagonal mesoporous silica catalyst used in the adsorption process affected the gossypol adsorption efficiency. The effect of the aluminium-hexagonal mesoporous silica catalyst dose on the adsorption efficiency is shown in Fig. 6. At ambient temperature, with $\mathrm{Si} / \mathrm{Al}=50$ of aluminium-hexagonal mesoporous silica catalyst, $2 \mathrm{~g}$ cottonseed oil and the gossypol content of $0.17 \mathrm{mg} / \mathrm{g}$. The mixture was stirred at $200 \mathrm{rpm}$ for $0.5 \mathrm{~h}$. The 


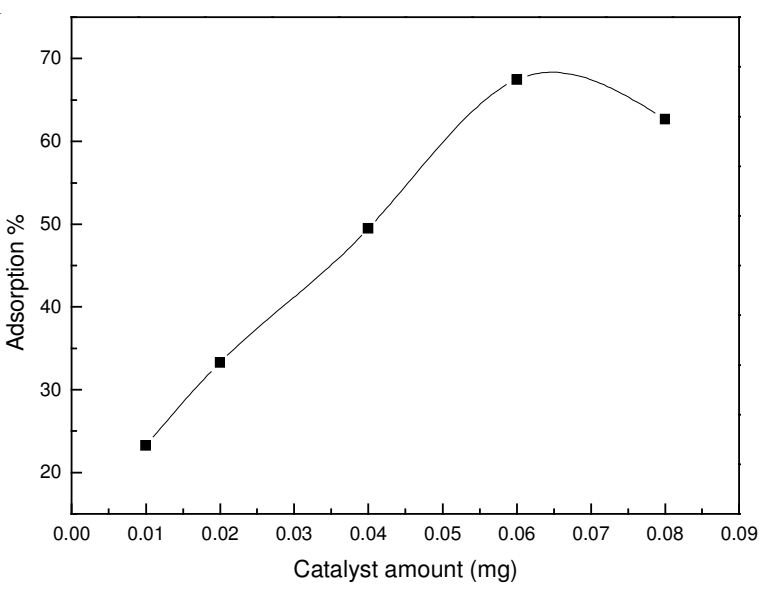

Fig. 6. Effect of catalyst amount on the adsorption of gossypol

adsorption efficiency of gossypol increased with increasing aluminium-hexagonal mesoporous silica catalyst amount. When the aluminium-hexagonal mesoporous silica catalyst amount was $0.01 \mathrm{~g}$, the gossypol adsorption efficiency was $23.3 \%$; the amount was $0.02 \mathrm{~g}$, the gossypol adsorption efficiency was $33.3 \%$; the amount was $0.04 \mathrm{~g}$, the gossypol adsorption efficiency was $49.5 \%$; the amount was $0.06 \mathrm{~g}$, the gossypol adsorption efficiency was $67.5 \%$ and the amount was $0.08 \mathrm{~g}$, the gossypol adsorption efficiency was $62.7 \%$. While addition of additional aluminium-hexagonal mesoporous silica catalyst, the gossypol adsorption efficiency did not increase.

The effects of time for gossypol adsorption show in the Fig. 7. At the room temperature, with $\mathrm{Si} / \mathrm{Al}=50$ of aluminiumhexagonal mesoporous silica catalyst, $2 \mathrm{~g}$ cottonseed oil and the gossypol content of $0.17 \mathrm{mg} / \mathrm{g}$, the amount of aluminiumhexagonal mesoporous silica catalyst was $0.06 \mathrm{~g}$. The mixture was stirred at $200 \mathrm{rpm}$ for different time (10-50 min). The mixture was stirred for 10 min the gossypol adsorption was $26.92 \%$; stirred for 20 min the gossypol adsorption was 44.99 $\%$; stirred for 30 min the gossypol adsorption was $63.14 \%$; stirred for $40 \mathrm{~min}$ the gossypol adsorption was $65.32 \%$ and stirred for $50 \mathrm{~min}$ the gossypol adsorption was $61.04 \%$. The adsorption increased with reaction time and gradually peaked at $30 \mathrm{~min}$ (Fig. 7).

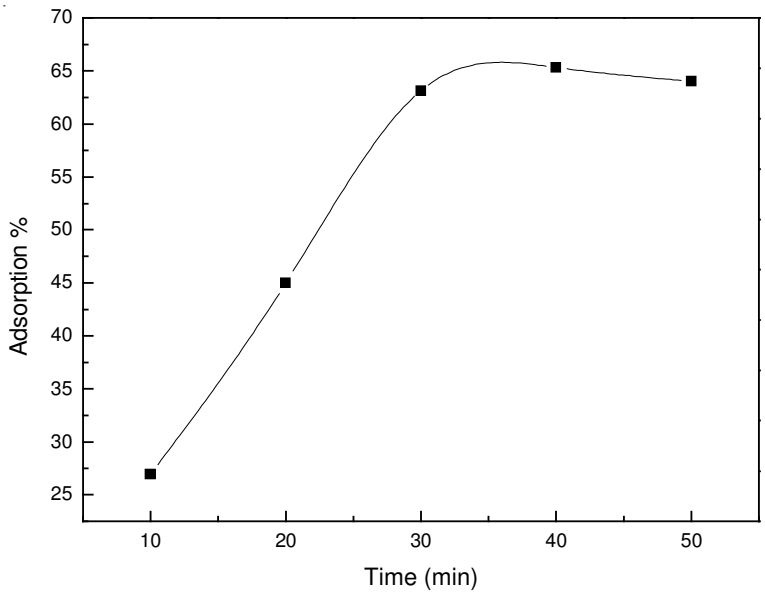

Fig. 7. Effect of reaction time on the adsorption of gossypol

\section{Conclusion}

We have synthesized mesoporous molecular sieves aluminium-hexagonal mesoporous silica catalyst with different $\mathrm{Si} / \mathrm{Al}$ ratios and synthesized using dodecylamine as surfactant by neutral templating method. The aluminiumhexagonal mesoporous silica catalysts samples were examined by XRD and BET that shows good dispersion. With the increase in the content of alumina, the adsorption of the catalysts increased. When Al loading on hexagonal mesoporous silica was $\mathrm{Si} / \mathrm{Al}=50$, the amount of the catalyst was $0.06 \mathrm{mg}$ for gossypol adsorption process of $30 \mathrm{~min}$, the adsorption rate more than $60 \%$.

\section{ACKNOWLEDGEMENTS}

The authors acknowledged the support of Doctor's Special Fund of Xinjiang Production and Construction Corps (No. 2010JC13), Initial Fund for high-level talents of Shihezi University (RCZX20036), Program for Innovation Team Development of Xinjiang Bingtuan (2011CC001).

\section{REFERENCES}

1. J.A. Kenar, J. Am. Oil Chem. Soc., 83, 269 (2006).

2. Y.F. Cai, H. Zhang, Y. Zeng, J.C. Mo, J.K. Bao, C. Miao, J. Bai, F. Yan and F. Chen, J. Biosci., 29, 67 (2004).

3. F.H. Smith, J. Am. Oil Chem. Soc., 44, 267 (1967).

4. R.J. Hron Sr., M.S. Kuk and G. Abraham, J. Am. Oil Chem. Soc., 67, 182 (1990).

5. L.C. Berardi and V.L. Frampton, J. Am. Oil Chem. Soc., 34, 399 (1957).

6. L.C. Berardi and V.L. Frampton, J. Am. Oil Chem. Soc., 38, 51 (1961).

7. M.S. Kuk and R. Tetlow, J. Am. Oil Chem. Soc., 82, 905 (2005).

8. W.A. Pons Jr., J.C. Kuck and V.L. Frampton, J. Am. Oil Chem. Soc., 38, 104 (1961).

9. P. Falaras, F. Lezou, G. Seiragakis and D. Petrakis, Clays Clay Miner, 48, 549 (2000).

10. R. Kamga, G.J. Kayem and P.G. Rouxhet, J. Colloid. Interface Sci., 232, 198 (2008).

11. W. Zhao, J.J. Li, C. He, L. Wang, J.L. Chu, J.K. Qu and Z.P. Hao, Catal. Today, 158, 427 (2010).

12. N. Chamkasem, J. Am. Oil Chem. Soc., 65, 1601 (1988).

13. R. Mokaya and W. Jones, J. Catal., 172, 211 (1997).

14. P.T. Tanev and T.J. Pinnavaia, Science, 267, 865 (1995).

15. T. Chiranjeevi, G.M. Kumaran, J.K. Gupta and G.M. Dhar, Thermochim. Acta, 443, 87 (2006).

16. X.Y. Chen, L.M. Huang, G.Z. Ding and Q.Z. Li, Catal. Lett., 44, 123 (1997).

17. S.M. Rlseman, F.E. Massoth, G.M. Dhar and E.M. Eyring, J. Phys. Chem., 86, 1760 (1982).

18. L. Forni, Catal. Rev., 8, 65 (1974). 